\title{
BMJ Open Patient-related healthcare disparities in the quality of acute hip fracture care: a 10-year nationwide population-based cohort study
}

\author{
Pia Kjær Kristensen (D) , ${ }^{1,2}$ Anne Mette Falstie-Jensen, ${ }^{3}$ Morten Madsen, ${ }^{2}$ \\ Søren Paaske Johnsen ${ }^{4}$
}

To cite: Kristensen PK, FalstieJensen AM, Madsen M, et al. Patient-related healthcare disparities in the quality of acute hip fracture care: a 10-year nationwide populationbased cohort study. BMJ Open 2021;11:e051424. doi:10.1136/ bmjopen-2021-051424

- Prepublication history and additional supplemental material for this paper are available online. To view these files, please visit the journal online (http://dx.doi.org/10.1136/ bmjopen-2021-051424).

Received 18 March 2021 Accepted 09 December 2021

Check for updates

(C) Author(s) (or their employer(s)) 2021. Re-use permitted under CC BY-NC. No commercial re-use. See rights and permissions. Published by BMJ.

${ }^{1}$ Department of Orthopedic Surgery, Regional Hospital Horsens, Horsens, Denmark ${ }^{2}$ Department of Clinical Epidemiology, Aarhus University, Aarhus, Denmark

${ }^{3}$ National Clinical Registries, Danish Regions, Aarhus,

Denmark

${ }^{4}$ Danish Center for Clinical Health Services Research, Aalborg Universitet, Aalborg, Denmark

Correspondence to Pia Kjær Kristensen; pkkr@clin.au.dk

\section{ABSTRACT}

Objectives To characterise and quantify possible patientrelated disparities in hip fracture care including temporal changes.

Design Population-based cohort study.

Setting All Danish hospitals treating patients with hip fracture.

Participants 60275 hip fracture patients from 2007 to 2016.

Interventions Quality of care was defined as fulfilment of eligible care process measures for the individual patient recommended by an expert panel. Using yearly logistic regression models, we predicted the individual patient's probability for receiving high-quality care, resulting in a distribution of adjusted probabilities based on age, sex, comorbidity, fracture type, education, family mean income, migration status, cohabitation status, employment status, nursing home residence and type of municipality. Based on the distribution, we identified best-off patients (ie, the $10 \%$ of patients with the highest probability) and worst-off patients (ie, the $10 \%$ of patients with the lowest probability). We evaluated disparities in quality of care by measuring the distance in fulfilment of outcomes between the best-off and worst-off patients.

Primary and secondary outcome measures The primary outcome was fulfilment of all-or-none, defined as receiving all relevant process measures. Secondary outcomes were fulfilment of the individual process measures including preoperative optimisation, early surgery, early mobilisation, assessment of pain, basic mobility, nutritional risk and need for antiosteoporotic medication, fall prevention and a postdischarge rehabilitation programme.

Results The proportion of patients receiving high-quality care varied over time for both best-off and worst-off patients. The absolute difference in percentage points between the best-off and worst-off patients for receiving all-or-none of the eligible process measures was 12 (95\% Cl 6 to 18) in 2007 and 23 (95\% Cl 19 to 28) in 2016. Disparities were consistent for a range of care processes, including assessment of pain, mobilisation within 24 hours, assessment of need for antiosteoporotic medication and nutritional risk assessment.

Conclusions Disparity of care between best-off and worst-off patients remained substantial over time.
Strengths and limitations of this study

- The first large-scale nationwide study of overall patient-related disparity in the quality of hip fracture care.

- New way of analysing disparities in care by measuring the distance in fulfilment of care recommendations between the 10th and 90th percentile in the distribution of adjusted probabilities for receiving high-quality care.

- The study quantifies unjustified differences in quality of care over a 10 -year period.

Other aspects of quality of care, including the patient perspective, were not examined.

\section{INTRODUCTION}

Avoiding disparities in quality of care is a high priority in advanced healthcare systems. ${ }^{1}{ }^{2}$ Patients should receive adequate healthcare when needed, irrespectively of their gender, age, race, comorbidity and socioeconomic status. To reach this goal, many countries have implemented strategies for improving quality that involve clinical guidelines, continuous quality monitoring, systematic auditing and accreditation, among others. ${ }^{3-7}$ Patients with hip fracture are often singled out as targets for quality-improvement initiatives because multidisciplinary acute care is essential to their prognosis and because the hip fracture patients' care pathway is highly standardised. ${ }^{89}$ Thus, a favourable prognosis hinges on multiple factors, for example, multidisciplinary care processes including preoperative optimisation, early surgery, early mobilisation, assessment of; pain, functional level, nutritional risk and need for antiosteoporotic medication, fall prevention and preparation of a postdischarge rehabilitation programme. ${ }^{8} 9$ Furthermore, several countries, including Sweden, Norway, Finland, the UK, Italy and Denmark, have implemented 
continuous performance monitoring of hip fracture care. $^{10-16}$ Although these initiatives have existed for many years, evidence has focused mainly on benchmarking and public disclosure of performance data at the hospital level as an established way of improving quality of care. ${ }^{37-19}$ Only a few studies have examined disparity in quality of care between subgroups of hip fracture patients. ${ }^{20-25}$ Previous research has focused on individual patient demographics, including age, sex, socioeconomic status and the association of these characteristics with quality of care rather than on patients' entire prognostic profile. ${ }^{22} 232627$ We; therefore, do not know which levels of disparities patients may encounter in the healthcare.

The aim of this study was to characterise and quantify the association between a broad range of possible patientrelated disparities and the quality of hip fracture care, including temporal changes.

\section{METHODS}

We conducted a population-based cohort study using prospectively collected data from Danish medical registries. Informed participant consent is not required for registry-based studies in the Nordic countries. ${ }^{28}$ Denmark is located in Northern Europe and has 5.8 million inhabitants. The public healthcare services are financed by taxes and all residents have free access to healthcare. All residents have a unique civil registration number which is used in all healthcare contacts. ${ }^{29}$ The civil registration number allows unambiguous linkage between all administrative and healthcare registries. All emergencies, including hip fractures, are exclusively treated at the nearest public hospital. ${ }^{30}$ The cohort of hip fracture patients was identified through the Danish Multidisciplinary Hip Fracture Registry (DMHFR). ${ }^{16}$

\section{Data sources}

The DMHFR is a national clinical quality register on all patients aged $\geq 65$ admitted with femoral fractures and treated with surgery from 2003 and onwards. ${ }^{16}$ The DMHFR contains patient-level data on process performance measures reflecting current guidelines for in-hospital care. The register also contains sociodemographic and clinical characteristics on all patients. By law, reporting to the DMHFR is mandatory for all departments treating hip fracture patients, and data are entered prospectively by the care staff starting from patient admission. ${ }^{1031}$

Patient-level data on clinical characteristics and process performance obtained from the DMHFR were supplemented with data from the nationwide Danish National Patient Registry, ${ }^{32}$ the Civil Registry System ${ }^{29}$ and socioeconomic registries from Statistic Denmark. ${ }^{33}$ The Danish National Patient Registry holds data on all nonpsychiatric hospital admissions since 1977 and all outpatient and emergency room visits since 1995, recorded according to the International Classification of Diseases (ICD) 8th Revision until the end of 1993 and the 10th Revision (ICD-10) thereafter. ${ }^{29}$ The Civil Registry System holds records of changes in vital status and migration for the entire Danish population since 1968, which allows complete follow-up on mortality in this study irrespective of place of death. ${ }^{29}$ Statistic Denmark holds detailed information on residents in Denmark, including level of education, employment status household income, migration status, cohabitant status, nursing home residence and regional and municipality residency. ${ }^{34}$ All registers are updated yearly.

\section{Study population}

We included all patients aged $\geq 65$ years admitted with femoral fractures (ICD-10 codes: medial (S720), pertrochanteric (S721) or subtrochanteric (S722)), who were treated surgically with osteosynthesis or alloplastic in the period from 2007 to 2016 ( $\mathrm{N}=66577){ }^{35}$ To ensure sufficient information on previous income and comorbidity we excluded patients living in Denmark for less than 5 years prior to the date of the hip fracture surgery. Furthermore, we excluded patients for the following reasons: missing information on population registry, family income or surgery. Patients with multiple events during the study period were only included with data from their first event. Furthermore, patients treated in January and February 2010 and in December 2014 were excluded due to changes in the reporting system. Lastly, patients registered at hospital departments with less than 10 hip fracture patients per year were excluded, as these low volume departments may have less experience in data reporting and which may impair the data quality. To ensure high comparability of clinical needs among the included patients, we restricted to patients, who were relevant for at least $50 \%$ of the recommended care processes in the year of their index admission. The final hip fracture cohort included 60275 patients (figure 1).

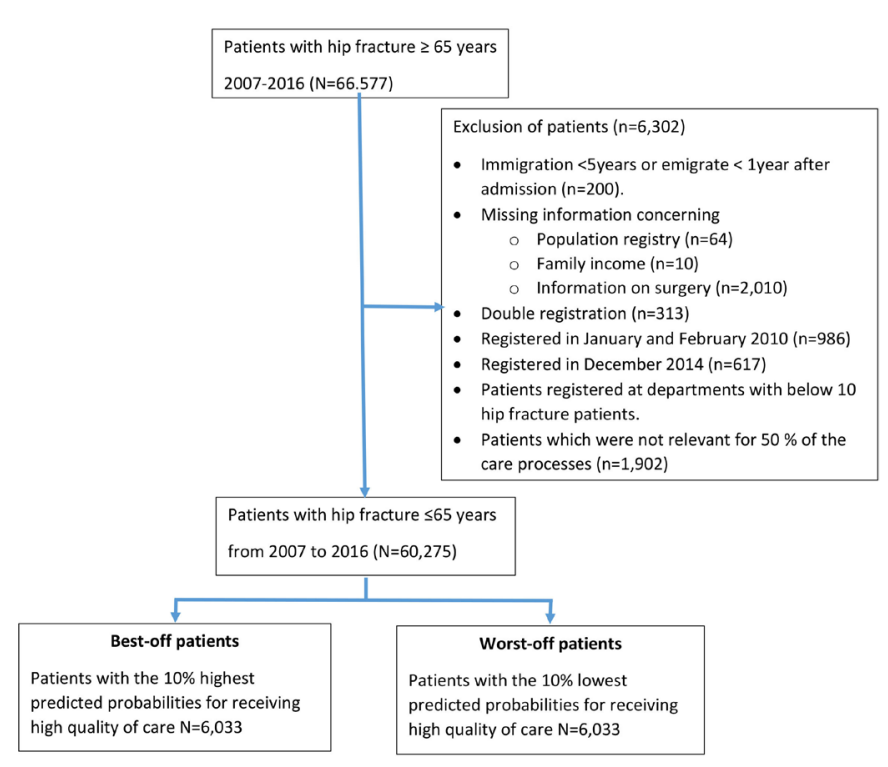

Figure 1 Flow chart. 


\begin{tabular}{|c|c|c|c|c|c|c|c|c|c|c|}
\hline & 2007 & 2008 & 2009 & 2010 & 2011 & 2012 & 2013 & 2014 & 2015 & 2016 \\
\hline Pain assessment & + & + & + & + & + & + & + & + & & \\
\hline Mobilization within 24 hours & & & & + & + & + & + & + & & + \\
\hline Assessment of nutrition risk & + & + & + & & & & & & + & + \\
\hline $\begin{array}{l}\text { Assessment of need for osteoporotic } \\
\text { medication }\end{array}$ & & & & + & + & + & + & + & + & + \\
\hline Fall prevention & & & & + & + & + & + & + & + & + \\
\hline Prevention of osteoporotic fractures & + & + & + & & & & & & & \\
\hline Post discharge rehabilitation program & + & + & + & + & + & + & + & + & & + \\
\hline $\begin{array}{l}\text { Assessment of functional level at } \\
\text { admission }\end{array}$ & + & + & + & & & & + & + & + & + \\
\hline Assessment of functional level at discharge & + & + & + & + & + & + & + & + & + & + \\
\hline Time to surgery within 24 hours & & & & & & & & & + & + \\
\hline Time to surgery within 36 hours & & & & & & & & & + & + \\
\hline Preoperative optimization & & & & & & & & & & + \\
\hline
\end{tabular}

Figure 2 Overview of process performance measures in the time period.

\section{Quality of acute hip fracture care}

The quality of acute hip fracture care has been measured in the DMHFR since 2003. A multidisciplinary steering committee which comprised experienced clinicians appointed by relevant scientific societies and professional associations has selected a number of process performance measures to assess quality of care. The process performance measures reflect recommended basic care from the national clinical guideline for in-hospital care, which are continuous monitored in the registry by clinicians. The recommended care processes examined during the study period are shown in figure 2 . The recommendations have changed over time due to changes in evidence and clinical practice. Patients are classified as eligible or ineligible for each care process according to clinical judgement based on detailed data definitions. Annually, the quality of care assessed at the hospital level are released in a report and a structured audit process is carried out to assess critically the quality of the dataset and results. We defined the quality of care using two approaches: (1) fulfilment of the composite all-or-none measure for patients relevant for a minimum $50 \%$ of the process performance measures and (2) fulfilment of the individual process performance measures. Fulfilment of all-or-none required fulfilment of all relevant process performance measures for the individual patient, that were valid in a given year. Otherwise, patients were categorised as not fulfilled. Therefore, all-or-none was a measure for whether a patient received the complete recommended bundle of care.

\section{Patient characteristics}

Patient characteristics included demographic, lifestyle and socioeconomic factors in addition to fracture type because these factors have been shown to be associated with the probability of receiving optimal treatment and with clinical outcome following hip fracture (table 1)..$^{20-23} 2627$ We used the Charlson Comorbidity Index (CCI) to summarise each patient's 10-year comorbidity history. ${ }^{36}$ The CCI categorises comorbidities based on ICD codes obtained from the Danish National Patient Registry. Each comorbidity category has an associated weight based on the adjusted risk of mortality; the sum of all the weights yields a single comorbidity score for each patient. Fracture type was classified as either nondisplaced medial fracture, displaced medial or pertrochanteric and subtrochanteric fracture, ${ }^{37}$ or missing fracture type (missing fracture type only for the years 2010 and forward due to a change in the digital platform for reporting). To account for yearly variation in family income, we calculated the average yearly total income in the 5 years preceding admission for each patient and their cohabiting partner and categorised these data into three tertiles of increasing income. ${ }^{22}$ We classified educational achievement and employment status according to the nomenclature used in Statistic Denmark. ${ }^{22}$ We dichotomised migration status into migrant versus native due to low numbers of migrants among hip fracture patients.

\section{Statistical methods}

For each patient, we calculated the all-or-none as a measure of fulfilment of all relevant care processes 
Table 1 Patient characteristics overall and for best-off and worst-off patients

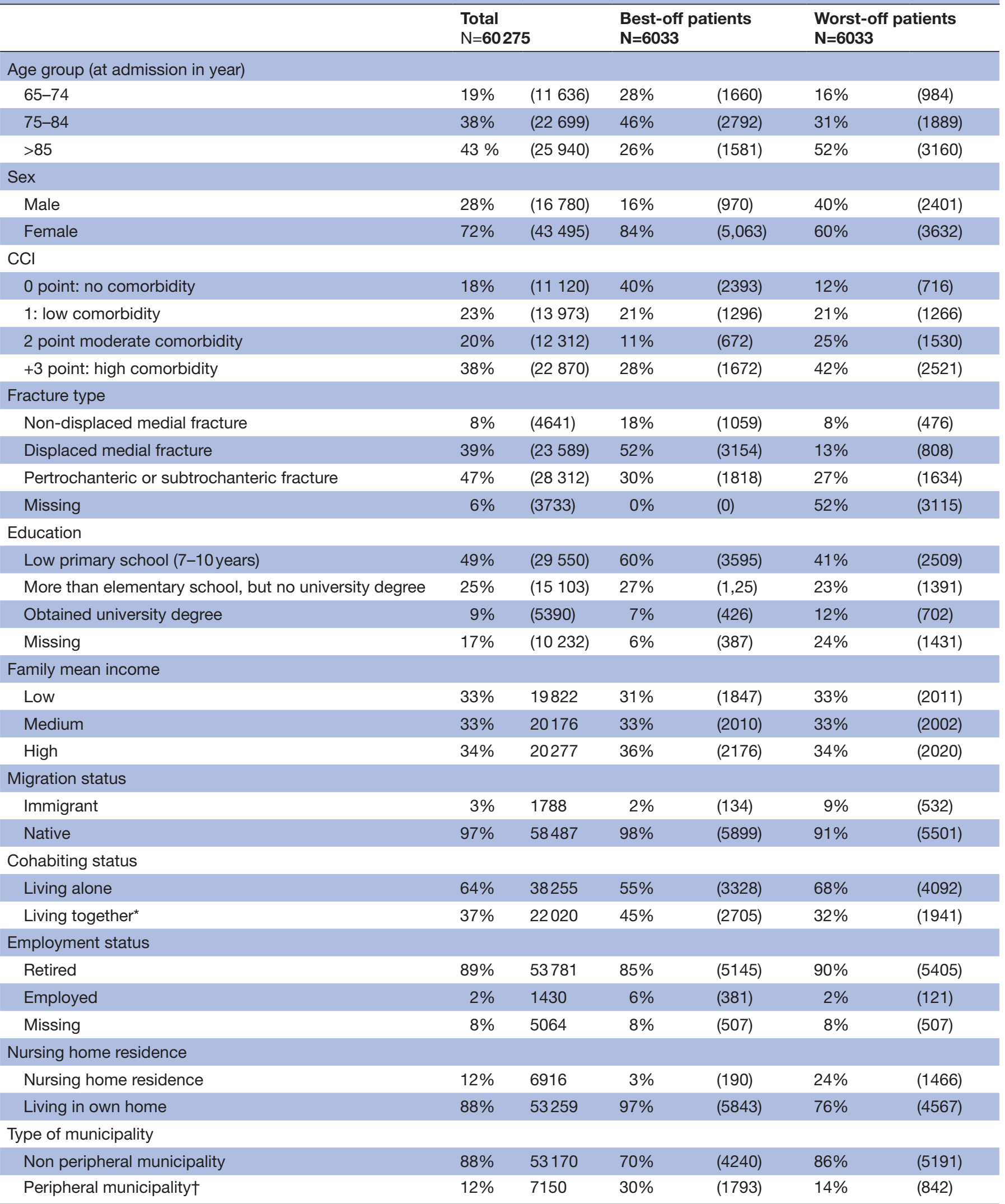

${ }^{*}$ Married couple, other types of couples or households including several families.

†Defined by the ministry of cities, residence and rural districts: Patients living in the municipalities: Lolland, Bornholm, Langeland, Æ Ærø, Tønder, Varde, Lemvig, Struer, Norddjurs, Samsø, Ringkøbing-Skjern, Morsø, Skive, Thisted, Vesthimmerland or Læsø.

$\mathrm{CCl}$, Charlson Comorbidity Index. 
included for that year. We identified best-off and worst-off patients for each calendar year. We used a multivariable logistic regression model taking all patient characteristics into account to predict the probability of fulfilment of the all-or-none composite. The multivariable logistic regression model is presented in online supplemental method. We calculated the predicted probability for receiving high-quality care defined as fulfilment of the all-or-none composite for each patient, which yielded a distribution of adjusted probabilities. Based on each patient's predicted probability, we identified two categories of patients according to their individual chance of receiving high or low quality of care corresponding to the two most extreme deciles; hereafter designated best-off and worst-off patients. The best-off patients were the ones with the highest predicted chance of fulfilment of the allor-none composite, corresponding to patients from the 90th percentile or patients above this percentile in the predicted chance distribution. By contrast, the worst-off patients had the lowest chance of fulfilment of the allor-none composite and thus fell into the lowest 10th percentile. We then evaluated patient-level disparities in receiving high-quality hip fracture care by measuring the distance between the 10th and the 90th percentile in fulfilment of the all-or-none composite as well as individual process performance measures. We evaluated the ability of the logistic prediction models to discriminate between groups by deriving the $\mathrm{C}$-index and calibration using receiver operator curve analyses and calibration curves.

First, we examined patient characteristics for best-off and worst-off patients by calendar years.

Second, we quantified possible patient-related disparities in the quality of hip fracture care as the yearly difference in fulfilment of the all-or-none composite, as well as the differences in fulfilment of individual care processes.
Third, performing a sensitivity analysis, we repeated the analyses excluding all patients with missing information to explore whether missing information could explain our results.

\section{Patient involvement statement}

This research was done without patient involvement. Patients were not invited to comment on the study design and were not consulted to develop patient-relevant outcomes or interpret the results. Patients were not invited to contribute to the writing or editing of this document for readability or accuracy.

\section{RESULTS}

The overall hip fracture cohort included 60275 patients. Based on the logistic regression models, the best-off and worst-off groups each comprised 6033 patients. Overall patient characteristics for the entire population and the best-off and worst-off patients are presented in table 1 . Throughout the years, best-off patients were typically females between 75 and 84 years (online supplemental table 1). We observed no clear pattern for comorbidity and type of fracture for best-off patients (online supplemental table 1). In contrast, among worst-off patients, we observed a male preponderance and more were 85 years or older and had high comorbidity levels (online supplemental table 1). In addition, for a majority of the worst-off patients, registration of fracture type and type of education was missing for many of the worst-off patients (online supplemental table 1). Best-off and worst-off patients did not differ according to employment, household income or cohabiting status.

The proportion of patients receiving high quality of care defined as all-or-none varied over the years for both patient groups, as shown in figure 3. Best-off and worst-off

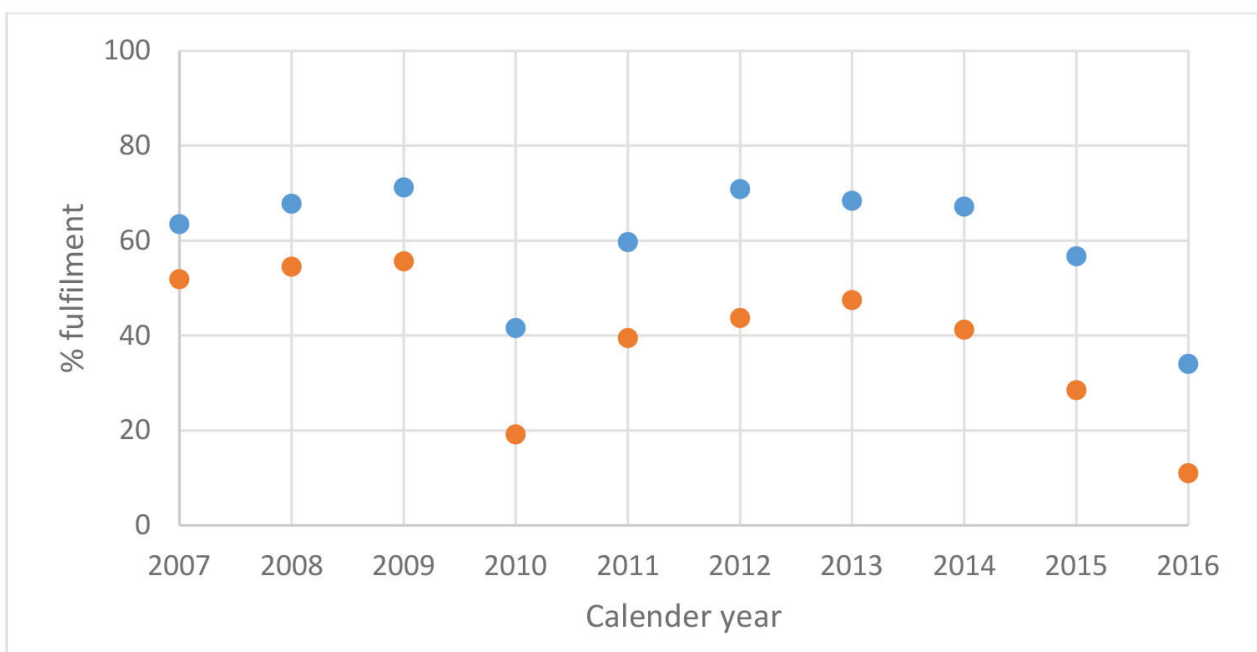

Best-off patients Worst-off patients

Figure 3 The proportion of best-off- and worst-off patients, who fulfilled the all-or-none by calendar year. 
patients showed the same pattern with an increase in fulfilment of quality criteria until 2010 followed by a notable drop. In 2012, best-off patients had the same fulfilment as in 2009; however, this was not the case for the worst-off patients. Consequently, the difference in percentage points between best-off and worst-off patients for receiving the all-or-none composite rose over the years from 12 percentage points (95\% CI 6 to 18) in 2007 to 23 percentage points (95\% CI 19 to 28) in 2016. The greatest difference was in 2015, with 28 percentages points (95\% CI 23 to 33), whereas the lowest was in 2007. We primarily observed differences in quality of care between best-off and worst-off patients in four individual care processes: assessment of pain, mobilisation within 24 hours, assessment of need for antiosteoporotic medication and nutritional risk assessment (figure 4). Fulfilment of assessment of functional level and joining a postdischarge rehabilitation programme increased for both patient categories during the study period; and so did prevention of osteoporotic fractures, which was applicable early in the study period. No clear pattern was seen for the care processes time to surgery and preoperative optimisation, which were applicable only for the two last years and 2016, respectively. The exact numbers for the figures are provided in online supplemental table 2 . The sensitivity analysis, excluding patients with missing information on fracture type, showed a lower level of disparity in quality of care between the best-off and the worst-off patients (online supplemental figure 1).

The final models for predicting fulfilment of the allor-none composite had a C-index between 0.55 and 0.60 , indicating that the models provided a poor-to-moderate discrimination between different patients. However, the calibration curves overlapped the identity line in the histograms as illustrated in online supplemental figure 2 , indicating good model calibration.

\section{DISCUSSION}

This population-based study among hip fracture patients in Denmark shows that disparity in the quality of care among hip fracture patients has remained substantial over time. The disparity was observed consistently for a range of individual recommended care processes, including assessment of pain, mobilisation within 24 hours, assessment of need for antiosteoporotic medication and nutritional risk assessment.

The strengths of this study include the use of a large, well-characterised nationwide cohort with national coverage of prospectively collected data, the use of the unique individual personal registration number ensuring no loss to follow-up and linkage between national registries with detailed information. Furthermore, the care processes used represent basic hip fracture care recommended by experienced clinicians and in accordance with international standards ${ }^{38}$; and the processes have been shown to be associated with improved outcome. ${ }^{89}$ Several initiatives were taken to handle potential heterogeneity in the individual patients' needs. Only eligible care processes for the individual patient were included in the analysis as staff was able to exclude patients ineligible for the recommended care process, for example, patients with dementia who would be incapable of reporting their level of pain. We cannot exclude the possibility that the clinical assessment of the eligibility criteria for individual patients may have varied. However, the included process performance measures reflect basic care elements for which only a small proportion of hip fracture patients were considered ineligible. In addition, in the analyses we only included patients who were relevant for a minimum of half of the care processes. Hence, the clinical need for fulfilment of the process performance measures was considered comparable among best-off and worst-off patients, and any non-differential misclassification of eligibility would most likely have biased our findings in a conservative direction. The predictive performance of the logistic regression models was poor to moderate, indicating that factors not available to us influenced the likelihood of receiving some dimension of recommended care. Still, the calibration curves showed that the models were well calibrated in the area where data were available. Furthermore, we observed substantial differences in patient characteristics and the received quality of care when comparing the best-off with the worst-off patients, even if the model showed suboptimal discriminative performance. Potential bias related to miscoding and misclassification in the database may have affected our results. In addition, information on fracture type and education was lacking for a substantial proportion of the worst-off patients. However, a sensitivity analysis excluding all patients with missing data confirmed the disparity between best-off and worst-off patients from the primary analysis. Data validity is highly prioritised in the DMHFR, which has detailed data definitions and auditing of data quality performed continuously at local and regional levels and annually at national level.

Ideally, the study should have been done in a setting where individual performance measures remained the same throughout the entire study period. However, attempts to improve quality of care are ever ongoing; and even though our approach produced a very heterogeneous measure, our use of the all-or-none composite represents the perceived professional definition of high quality of care at any given time during the study period.

Hip fracture patients have a high risk of serious complications and death. ${ }^{39}$ Thus, a growing body of evidence shows the importance of multidisciplinary interventions for the prognosis after hip fracture. ${ }^{8912384041}$ Quality of care requirements have therefore risen over time, and it has become more difficult for hospitals to fulfil the all-ornone composite. However, even though the requirements for quality of care have become more detailed and operational, disparity in care remains substantial.

In this study, we were able to discriminate between best-off and worst-off patients on the basis of age, sex and severity of disease, which corresponds to previously 

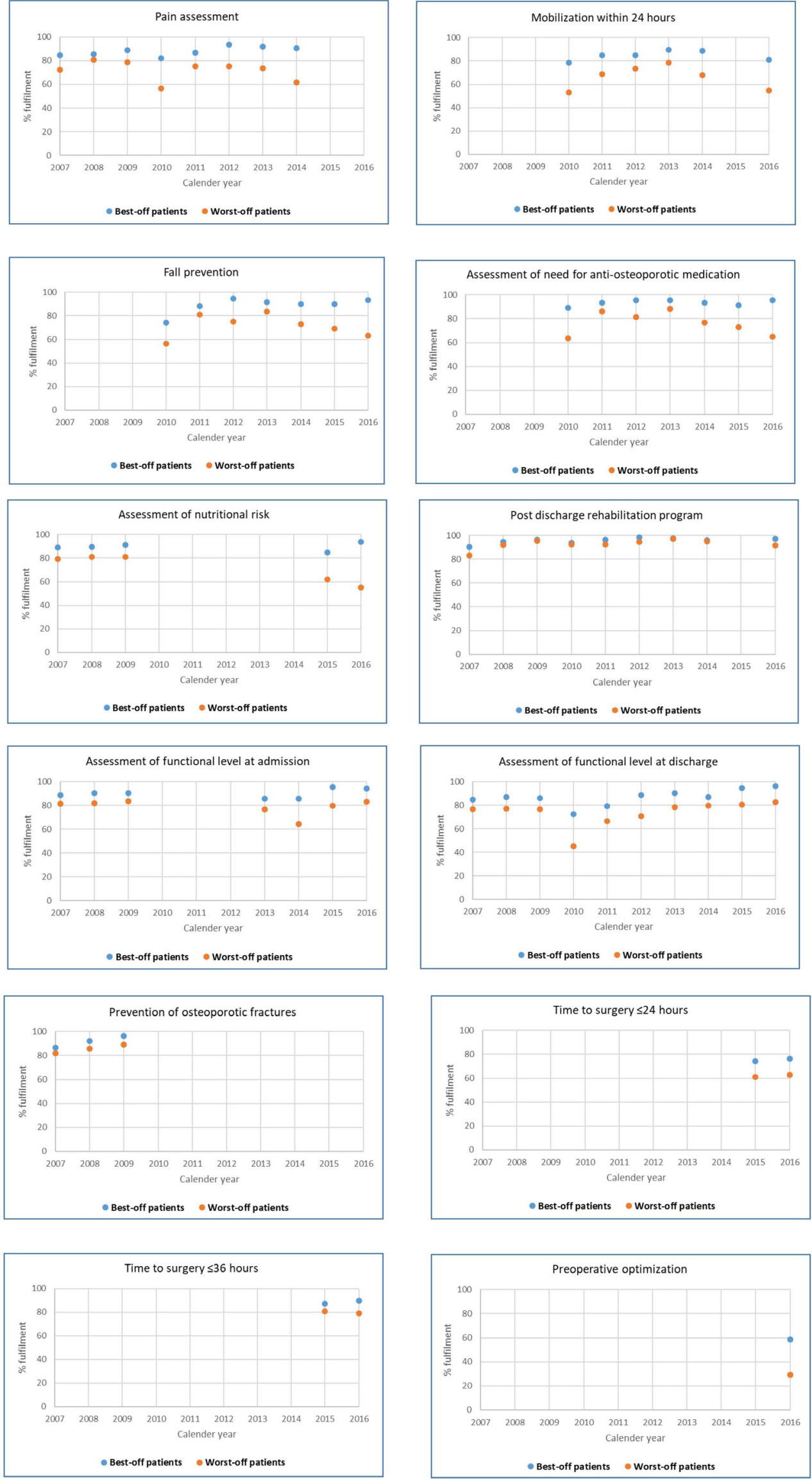

Figure 4 The proportion of best-off and worst-off patients, who fulfilled the individual process performance measure by calendar year. 
observed trends linking higher age and males with a lower chance of mobilisation within 24 hours after surgery. ${ }^{23}$ An important part of the disparity seems to be associated with missing registration of fracture type, indicating that deficient registration practices in medical records are associated with lower quality of care. Most other covariates were highly correlated and therefore not possible to attribute separate importance. The finding of minimal discrimination in relation to socioeconomic markers like employment, household income and education also corroborates with previous findings of no difference in the recommended hip fracture care in Denmark according to individual socioeconomic markers. ${ }^{22}$ This indicates that socioeconomic inequality in the quality of hip fracture care may not be a prominent problem in Denmark; however, substantial inequality still exists in the clinical outcomes, which leaves the healthcare system with an unmet challenge. ${ }^{22}$ Our study extends the understanding of patient-related disparity in the quality of hip fracture care as it quantifies the overall sum of unjustified difference. The overall size of disparity in healthcare is an important issue that deserves further scrutiny, not least since the healthcare system has sought to minimise the disparity in quality of care through implementation of clinical guidelines and continuous monitoring in recent decades.

Much effort has been made through the years to standardise treatment for patients with similar needs, including the introduction of universal patient rights; however, our study shows that it is difficult to ensure uniform high-quality care for all hip fracture patients even in tax-financed healthcare system like the Danish system. The lack of systematic monitoring of differences in quality of care among vulnerable patient groups makes it inherently difficult to identify potential problems. Our results, therefore, highlight the need for detailed monitoring of the quality of care among subgroups of hip fracture patients to ensure that vulnerable patient groups also benefit from the advances in hip fracture care seen in recent years.

In conclusion, this nationwide study shows disparity in the quality of care among hip fracture patients. The size of the disparity has remained substantial despite changes in clinical practice and the introduction of clinical guidelines. However, reducing disparities in care should not be the sole target as the overall quality of care needs to be improved for all types of hip fracture patients.

\section{Twitter Pia Kjær Kristensen @pia_kjar}

Acknowledgements We thank the staff of the hospital departments caring for patients with hip fracture for their continuous effort and contribution to acquisition of the data in the registries. Besides, we thank Thomas Bøjer Rasmussen for substantial help in analysing data and Johnny Kahlert for helpful comments and suggestions.

Contributors PKK: design of methodology, literature search, data interpretation, writing up original draft preparation, final approval of the version to be published. AMF-J: design of methodology, project administration, visualisation of tables, data interpretation, writing, reviewing and editing, and final approval of the version to be published. MM: design of methodology, data curation, data analysis, data interpretation, writing, reviewing and editing, and final approval of the version to be published. SPJ: conceptualisation and design, supervision, data interpretation, writing, reviewing and editing, and final approval of the version to be published. PKK is the guarantor of the manuscript

Funding This work was supported by a grant to PKK from the Health Research Fund of Central Denmark Region.

Disclaimer The financial sponsors played no role in the design, execution, analysis, interpretation of data, or writing of the study.

\section{Competing interests None declared.}

Patient consent for publication Not applicable.

Ethics approval This study was approved by The study was approved by the Danish Data Protection Agency (Aarhus University record number 2016-051-000001).

Provenance and peer review Not commissioned; externally peer reviewed.

Data availability statement Data may be obtained from a third party and are not publicly available. Data cannot be shared publicly because of ethical and data safety reasons. Data areavailable from the Danish Multidisciplinary Hip Fracture Registry and Statistics Denmark after approval of the research project by Danish Data Authorities and Steering Committee from the Danish Multidisciplinary Hip Fracture Registry.

Supplemental material This content has been supplied by the author(s). It has not been vetted by BMJ Publishing Group Limited (BMJ) and may not have been peer-reviewed. Any opinions or recommendations discussed are solely those of the author(s) and are not endorsed by BMJ. BMJ disclaims all liability and responsibility arising from any reliance placed on the content. Where the content includes any translated material, BMJ does not warrant the accuracy and reliability of the translations (including but not limited to local regulations, clinical guidelines, terminology, drug names and drug dosages), and is not responsible for any error and/or omissions arising from translation and adaptation or otherwise.

Open access This is an open access article distributed in accordance with the Creative Commons Attribution Non Commercial (CC BY-NC 4.0) license, which permits others to distribute, remix, adapt, build upon this work non-commercially, and license their derivative works on different terms, provided the original work is properly cited, appropriate credit is given, any changes made indicated, and the use is non-commercial. See: http://creativecommons.org/licenses/by-nc/4.0/.

ORCID iD

Pia Kjær Kristensen http://orcid.org/0000-0001-5473-9386

\section{REFERENCES}

1 World Health Organization. The WHO strategy on research for health, 2012.

2 World Health Organization. Delivering quality health services: a global imperative for universal health coverage. World Health Organization, 2018.

3 Campanella P, Vukovic V, Parente P, et al. The impact of public reporting on clinical outcomes: a systematic review and metaanalysis. BMC Health Serv Res 2016;16:296.

4 Mattke S, Kelley E, Scherer P. Health care quality indicators project: initial indicators report, 2006.

5 Falstie-Jensen AM, Bogh SB, Hollnagel E, et al. Compliance with accreditation and recommended hospital care-a Danish nationwide population-based study. Int J Qual Health Care 2017;29:625-33.

6 Falstie-Jensen AM, Bogh SB, Johnsen SP. Consecutive cycles of hospital accreditation: persistent low compliance associated with higher mortality and longer length of stay. Int $J$ Qual Health Care 2018;30:382-9.

7 Falstie-Jensen AM, Larsson $\mathrm{H}$, Hollnagel E, et al. Compliance with hospital accreditation and patient mortality: a Danish nationwide population-based study. Int J Qual Health Care 2015;27:165-74.

8 Kristensen PK, Thillemann TM, Søballe K, et al. Are process performance measures associated with clinical outcomes among patients with hip fractures? A population-based cohort study. Int J Qual Health Care 2016;28:698-708.

9 Nielsen KA, Jensen NC, Jensen CM, et al. Quality of care and 30 day mortality among patients with hip fractures: a nationwide cohort study. BMC Health Serv Res 2009;9:186-6963-9-186.

10 Mainz J, Krog BR, Bjørnshave B, et al. Nationwide continuous quality improvement using clinical indicators: the Danish national indicator project. Int J Qual Health Care 2004;16:i45-50. 
11 Sund $\mathrm{R}$, Juntunen $\mathrm{M}$, Lüthje $\mathrm{P}$, et al. Monitoring the performance of hip fracture treatment in Finland. Ann Med 2011;43:S39-46.

12 Patel NK, Sarraf KM, Joseph S, et al. Implementing the National hip fracture database: an audit of care. Injury 2013;44:1934-9.

13 Renzi C, Sorge C, Fusco D, et al. Reporting of quality indicators and improvement in hospital performance: the P.Re.Val.E. regional outcome evaluation program. Health Serv Res 2012;47:1880-901.

14 Thorngren K-G. National registration of hip fractures. Acta Orthop 2008;79:580-2.

15 Gjertsen J-E, Engesaeter LB, Furnes O, et al. The Norwegian hip fracture register: experiences after the first 2 years and 15,576 reported operations. Acta Orthop 2008;79:583-93.

16 Kristensen PK, Röck ND, Christensen HC, et al. The Danish multidisciplinary hip fracture registry 13 -year results from a population-based cohort of hip fracture patients. Clin Epidemiol 2020;12:9-21.

17 Pinnarelli L, Nuti S, Sorge C, et al. What drives hospital performance? The impact of comparative outcome evaluation of patients admitted for hip fracture in two Italian regions. BMJ Qual Saf 2012;21:127-34

18 Colais P, Di Martino M, Fusco D, et al. The effect of early surgery after hip fracture on 1-year mortality. BMC Geriatr 2015;15:141-0150140-y.

19 Colais P, Pinnarelli L, Fusco D, et al. The impact of a payfor-performance system on timing to hip fracture surgery: experience from the Lazio region (Italy). BMC Health Serv Res 2013;13:393-6963-13-393.

20 Ventura M, Fusco D, Bontempi K, et al. Regional outcome evaluation program (P.Re.Val.E.): reduction of inequality in access to effective health care in the Lazio region of Italy (2012-2015). PLoS One 2018;13:e0194972.

21 Colais P, Agabiti N, Fusco D, et al. Inequality in 30-day mortality and the wait for surgery after hip fracture: the impact of the regional health care evaluation program in Lazio (Italy). Int J Qual Health Care 2013;25:239-47.

22 Kristensen PK, Thillemann TM, Pedersen AB, et al. Socioeconomic inequality in clinical outcome among hip fracture patients: a nationwide cohort study. Osteoporos Int 2017;28:1233-43.

23 Kristensen PK, Johnsen SP, Mor A, et al. Is the higher mortality among men with hip fracture explained by sex-related differences in quality of in-hospital care? a population-based cohort study. Age Ageing 2017;46:193-9.

24 Prommik P, Kolk H, Maiväli Ülo, et al. High variability in hip fracture post-acute care and dementia patients having worse chances of receiving rehabilitation: an analysis of population-based data from Estonia. Eur Geriatr Med 2020;11:581-601.
25 Prommik P, Maiväli Ülo, Kolk H, et al. Causal variation modelling identifies large inter- and intra-regional disparities in physical therapy offered to hip fracture patients in Estonia. Disabil Rehabil 2021:1-9.

26 Perry DC, Metcalfe D, Griffin XL, et al. Inequalities in use of total hip arthroplasty for hip fracture: population based study. BMJ;2016:i2021.

27 Neuner JM, Zhang X, Sparapani R, et al. Racial and socioeconomic disparities in bone density testing before and after hip fracture. $J$ Gen Intern Med 2007;22:1239-45.

28 Ludvigsson JF, Håberg SE, Knudsen GP, et al. Ethical aspects of registry-based research in the Nordic countries. Clin Epidemiol 2015;7:491-508.

29 Schmidt M, Pedersen L, Sørensen HT. The Danish civil registration system as a tool in epidemiology. Eur J Epidemiol 2014;29:541-9.

30 Schmidt M, Schmidt SAJ, Adelborg K, et al. The Danish health care system and epidemiological research: from health care contacts to database records. Clin Epidemiol 2019;11:563-91.

31 Ministry D. The Danish health act legislation number 546 from 24 June 2005. Danish legislation number 546.

32 Schmidt M, Schmidt SAJ, Sandegaard JL, et al. The Danish national patient registry: a review of content, data quality, and research potential. Clin Epidemiol 2015;7:449-90.

33 Norredam M, Kastrup M, Helweg-Larsen K. Register-based studies on migration, ethnicity, and health. Scand J Public Health 2011;39:201-5.

34 Baadsgaard M, Quitzau J. Danish registers on personal income and transfer payments. Scand J Public Health 2011;39:103-5.

35 Committee NM-S. NOMESCO classification of surgical procedures. Copenhagen, 2011.

36 Andersen TF, Madsen M, Jørgensen J, et al. The Danish national Hospital register. A valuable source of data for modern health sciences. Dan Med Bull 1999;46:263-8.

37 Hjelholt TJ, Edwards NM, Vesterager JD, et al. The positive predictive value of hip fracture diagnoses and surgical procedure codes in the Danish multidisciplinary hip fracture registry and the Danish national patient registry. Clin Epidemiol 2020;12:123-31.

38 Hawkes D, Baxter J, Bailey C, et al. Improving the care of patients with a hip fracture: a quality improvement report. BMJ Qual Saf 2015;24:532-8.

39 Cummings SR, Melton LJ. Epidemiology and outcomes of osteoporotic fractures. Lancet 2002;359:1761-7.

40 Oldmeadow LB, Edwards ER, Kimmel LA, et al. No rest for the wounded: early ambulation after hip surgery accelerates recovery. ANZ J Surg 2006;76:607-11.

41 Laudicella M, Li Donni P, Smith PC. Hospital readmission rates: signal of failure or success? J Health Econ 2013;32:909-21. 